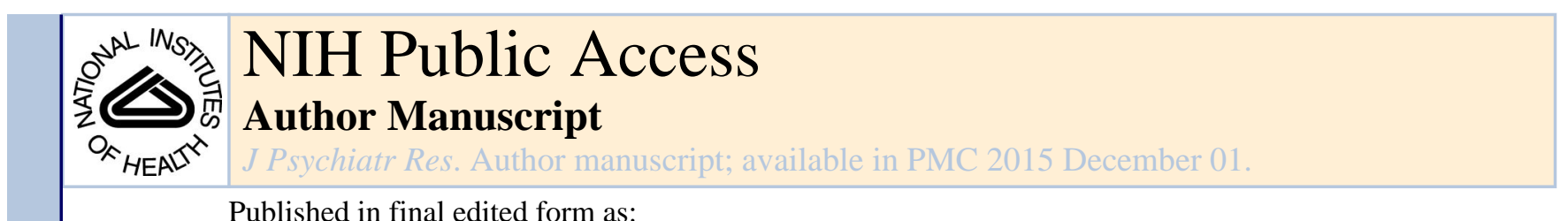

Published in final edited form as:

J Psychiatr Res. 2014 December ; 59: 220-228. doi:10.1016/j.jpsychires.2014.07.011.

\title{
Impact of Acamprosate on Plasma Amyloid- $\beta$ Precursor Protein in Youth: A Pilot Analysis in Fragile X Syndrome-Associated and Idiopathic Autism Spectrum Disorder Suggests a Pharmacodynamic Protein Marker
}

\author{
Craig A. Erickson ${ }^{1}$, Balmiki Ray², Bryan Maloney², Logan K. Wink¹, Katherine Bowers ${ }^{1}$, \\ Tori L. Schaefer ${ }^{1}$, Christopher J. McDougle ${ }^{3}$, Deborah K. Sokol ${ }^{2}$, and Debomoy K. Lahiri, ${ }^{2}$, \\ ${ }^{1}$ Cincinnati Children's Hospital Medical Center, Cincinnati, OH, USA \\ ${ }^{2}$ Department of Psychiatry, Institute of Psychiatric Research, Indiana University School of \\ Medicine, Indianapolis, IN, USA \\ ${ }^{3}$ Lurie Center for Autism, Massachusetts General Hospital, Harvard Medical School, Boston, MA, \\ USA
}

\begin{abstract}
Background-Understanding of the pathophysiology of autism spectrum disorder (ASD) remains limited. Brain overgrowth has been hypothesized to be associated with the development of ASD. A derivative of amyloid- $\beta$ precursor protein (APP), secreted APPa (sAPPa), has neuroproliferative effects and has been shown to be elevated in the plasma of persons with ASD compared to control subjects. Reduction in sAPPa holds promise as a novel molecular target of treatment in ASD. Research into the neurochemistry of ASD has repeatedly implicated excessive glutamatergic and deficient GABAergic neurotransmission in the disorder. With this in mind, acamprosate, a novel modulator of glutamate and GABA function, has been studied in ASD. No data is available on the impact of glutamate or GABA modulation on sAPPa function.
\end{abstract}

\footnotetext{
(C) 2014 Elsevier Ltd. All rights reserved.

"Corresponding Author: Debomoy K. Lahiri, Ph.D., Professor, Departments of Psychiatry and of Medical \& Molecular Genetics, Indiana University School of Medicine, Institute of Psychiatric Research, Neuroscience Research Building, 320 West 15th Street, NB 200C, Indianapolis, IN 46202-2266, USA, Tel: (317) 274-2706; Fax: (317) 231-0200.

Contributors: Drs. Erickson and Lahiri conceived the experiments, conducted the research, and wrote the manuscript. Dr. Sokol contributed to the writing and editing of the manuscript and participated in conceiving the experiments. Drs. McDougle, Ray, and Wink participating in conducting the research and assisted in manuscripts preparation. Drs. Schaefer, Bowers, and Maloney participated in data analysis and interpretation and assisted with manuscript preparation. All authors approve the final article as written.

Financial Disclosures: None (DKL, TS, KB, CJM, BR, DKS); Logan Wink, Consultant to Otsuka Pharmaceuticals; Craig Erickson, Equity in Confluence Pharmaceuticals, Consultant to the Roche Group and Alcobra Pharmaceuticals, Research Grant Support from the United States Department of Defense, The American Academy of Child and Adolescent Psychiatry, The John Merck Fund, Cincinnati Children's Hospital Medical Center, The Simons Foundation, the Angelman Syndrome Foundation, and the National Fragile X Foundation/United States Centers for Disease Control.

Publisher's Disclaimer: This is a PDF file of an unedited manuscript that has been accepted for publication. As a service to our customers we are providing this early version of the manuscript. The manuscript will undergo copyediting, typesetting, and review of the resulting proof before it is published in its final citable form. Please note that during the production process errors may be discovered which could affect the content, and all legal disclaimers that apply to the journal pertain.
} 
Methods-Plasma APP derivative levels pre- and post-treatment with acamprosate were determined in two pilot studies involving youth with idiopathic and fragile X syndrome (FXS)associated ASD. We additionally compared baseline APP derivative levels between youth with FXS-associated or idiopathic ASD.

Results-Acamprosate use was associated with a significant reduction in plasma sAPP(total) and sAPPa levels but no change occurred in A $\beta 40$ or A 442 levels in 15 youth with ASD (mean age: 11.1 years). Youth with FXS-associated ASD $(n=12)$ showed increased sAPPa processing compared to age-, gender- and IQ-match youth with idiopathic ASD ( $\mathrm{n}=11)$.

Conclusions-Plasma APP derivative analysis holds promise as a potential biomarker for use in ASD targeted treatment. Reduction in SAPP (total) and sAPPa may be a novel pharmacodynamic property of acamprosate. Future study is required to address limitations of the current study to determine if baseline APP derivative analysis may predict subgroups of persons with idiopathic or FXS-associated ASD who may respond best to acamprosate or to potentially other modulators of glutamate and/or GABA neurotransmission.

\section{Keywords}

amyloid precursor protein; autism spectrum disorder; acamprosate; glutamate; biomarker; GABA

\section{Introduction}

Autistic disorder (autism) is a childhood-onset neurodevelopmental disorder characterized by social skills and communication deficits combined with interfering repetitive behavior. Autism is the classic type of pervasive developmental disorder(American_Psychiatric_Association 2000), now termed autism spectrum disorder (ASD)(American_Psychiatric_Association 2013). Despite many recent efforts focused on identifying factors contributing to the development of ASD, more than $75 \%$ of cases of ASD remain idiopathic (McGrew et al. 2012).

Among biological factors associated with ASD, macrocephaly is a consistently replicated finding affecting up to 20\% of children with autism (Aylward et al. 2002; Aylward et al. 1999; Davidovitch et al. 1996; McCaffery and Deutsch 2005). Brain magnetic resonance imagery (MRI) studies in ASD have noted abnormal total brain volume enlargement in infants and toddlers (Courchesne et al. 2003; Courchesne et al. 2001; Courchesne and Pierce 2005; Sparks et al. 2002). Furthermore, early brain enlargement marked by increased surface area overgrowth seen in youth with autism may be associated with a disruption in cell adhesion (Hazlett et al. 2011). Among factors contributing to the brain overgrowth theory of ASD, pathophysiology, the potential contribution of dysregulation in amyloid- $\beta$ precursor protein (APP) metabolism has been proposed (Lahiri et al. 2013; Ray et al. 2011; Sokol et al. 2006; Sokol et al. 2011). APP has been associated with Alzheimer's disease (AD) where the amyloidgenic pathway of APP processing favors cleavage of APP by $\beta$-site APP cleaving enzyme or $\beta$-secretase (BACE1) resulting in neurotoxic amyloid- $\beta$ (A $\beta$ ) peptides consisting 40 and 42 amino acids residues (Lahiri et al. 2003). $A \beta 40$ and $A \beta 42$ are the major components of senile plaques associated with brain atrophy in AD. BACE1, which plays a rate-limiting role in the production of potentially toxic $A \beta$ within brain, is an important drug 
target for $\mathrm{AD}$, and indeed, several BACE1 inhibitors are tested in clinical drug trials (Lahiri et al, 2014).

APP is predominantly located at the synapse (Mattson and Furukawa 1998), produced in brain microglia, astrocytes, oligodendrocytes, and neurons (Mullan and Crawford 1993), and released in an activity driven fashion (Jolly-Tornetta et al. 1998). Activation of metabotropic glutamate receptor type 1 and type 5 (mGluR $1 / 5$ ) increases APP secretion in cell culture (Jolly-Tornetta et al. 1998). The highest levels of APP occur early in synaptogenesis (Priller et al. 2006) and peak before 1 month of age in rodents (Lahiri et al. 2002). APP has been implicated in neurite outgrowth (Mattson and Furukawa 1998; Mullan and Crawford 1993) and promotes growth cone development working in opposition to N-methyl-D-aspartate) NMDA and (a-amino-3-hydroxy-5-methyl-4-isoxazolepropionic acid) AMPA glutamate receptors' pruning effects on growth cones (Mattson and Furukawa 1998). As shown in cell culture studies, APP may block and reverse glutamatergic inhibition of dendrite outgrowth (Mattson 1994). APP has been linked to suppression of neuronal cell adhesion (Schubert et al. 1989) and overexpression of APP accelerates migration of neuronal precursor cells into the cortex (Young-Pearse et al. 2007). The non-amyloidgenic APP processing pathway involving cleavage by the a-secretase family of enzymes (such as ADAM 9, 10 and 17) is the predominant APP processing pathway leading to release of non-amyloidgenic secreted APPa (sAPPa) (Mattson 1994; Ray et al. 2011). Several reports have noted neurotrophic effects of sAPPa, including activity in inducing cellular proliferation including the proliferation of neural progenitor cells (Mattson 1997; Stein and Johnson 2003; Turner et al. 2003). Notably, sAPPa also activates microglia (Barger and Harmon 1997). Overall, APP and specifically sAPPa are prime candidates to contribute to synaptic disruption and brain overgrowth in ASD given the proteins' enhancement of neural proliferation. APP modulation and $A \beta$ have been shown to be a target of several drugs, including cholinesterase inhibitors and a partial NMDA receptor antagonist (memantine) (Greig et al. 2005; Lahiri et al. 1998; Lahiri et al. 1994; Alley et al. 2010).

There have been several reports on abnormalities in secreted APP and specifically sAPPa in the blood of youth with autism (Bailey et al. 2008; Ray et al. 2011; Sokol et al. 2006).

Higher levels of plasma sAPP total and sAPPa were identified in a small sample of young children with autism and aggressive behavior compared to less impaired youth with autism without aggressive behavior and control subjects (Sokol et al. 2006). In a follow-up report involving 16 youth with autism and 18 control subjects, a similar increase in sAPPa was found in children with severe autism compared to youth with milder cases of autism and neurotypical control subjects (Ray et al. 2011). In the same study, reduced levels of A $\beta 40$ and $A \beta 42$ were detected in the youth with severe autism compared to control subjects. In a study involving 25 youth with autism aged 2-5 years and matched control subjects mean plasma sAPPa was significantly elevated in those with autism; $60 \%$ of those with autism had elevations in sAPPa (Bailey et al. 2008). Considering these results together, elevation in plasma sAPP (total) and specifically sAPPa could be a marker of molecular dysregulation contributing to the pathophysiology of autism.

Alterations in brain APP have also been reported in idiopathic ASD. Wegiel and colleagues (2012) have shown abnormal intracellular accumulation and extracellular $\mathrm{A} \beta$ deposition in 
the brain of persons with ASD (Wegiel et al. 2012). APP expression in brain has been demonstrated to be altered dependent on subject age and brain region in post-mortem ASD specimens (Fatemi et al. 2013).

Monogenetic disorders associated with co-morbid ASD hold promise to provide insight in to the pathophysiology of idiopathic autism. Fragile X syndrome (FXS) is the most common single gene cause of ASD, responsible for approximately $3 \%$ of autism cases (Kosinovsky et al. 2005). The prevalence rate of ASD in FXS is estimated between $25 \%$ and $50 \%$, depending on the criteria utilized (Clifford et al. 2007; Garcia-Nonell et al. 2008; Hatton et al. 2006; Kaufmann et al. 2004). FXS results from a CGG triplet repeat expansion in the promoter region of the Fragile X Mental Retardation gene (FMR1) on the long arm of the X chromosome. This expansion leads to gene methylation and silencing and subsequent deficiency in Fragile X Mental Retardation Protein (FMRP) production. FMRP is a known repressor of neuronal mRNA translation (Darnell et al. 2011; Lee et al. 2010; Veneri et al. 2004; Zalfa et al. 2003; Zou et al. 2008) and thus is important to synaptic plasticity and regulation of local protein synthesis at the synapse (Bagni and Greenough 2005). Similar to reports in idiopathic ASD, children with FXS also exhibit early brain overgrowth (Hazlett et al. 2012). Additionally, FMRP has been demonstrated to regulate APP mRNA expression (De Rubeis and Bagni 2010; Westmark and Malter 2007). Specifically, FMRP mediates mGluR5-dependent translation of APP mRNA. In normal brain development, activation of mGluR5 neuroreceptors results in suppression of FMRP translational repression of APP, a phenomenon absent in FXS (Westmark and Malter 2007). Baseline APP levels are elevated in Fmrl knockout (KO) mouse synaptoneurosomes and primary neurons, and APP levels do not increase following mGluR5 stimulation (Westmark and Malter 2007). A preliminary study reported a relative elevation of sAPPa, $A \beta 40$, and $A \beta 42$ in 18 youth with FXS compared to age-matched control subjects (Lahiri 2011). Additionally, Westmark and colleagues (2011) have demonstrated abnormal levels of A $\beta 42$ in the plasma of persons with FXS. Findings from FXS point to enhanced translation of APP compared to potential specific enhancement of the sAPPa synthesis pathway noted in idiopathic ASD. Together, these data from monogenetic and idiopathic ASD converge to support the role of APP dysregulation, specifically excessive levels of sAPPa, in the pathophysiology of ASD. Given this, it is important to explore elevated sAPPa expression as a target of treatment in ASD. Conceptually, the three proteins APP, FMRP, and mGluR5 are proposed to serve as molecular links for ASD, AD, and FXS, and consequently any disruption in interaction of this "trinity" could lead to the disease phenotype (Lahiri et al. 2013). It may be that analyses of APP metabolites and APP processing enzymes hold promise as a target of treatment, pharmacodynamic marker of target engagement, and as a potential means to subgroup populations matched to potential treatments of interest.

Acamprosate is approved by the United States Food and Drug Administration (FDA) for the maintenance of abstinence from alcohol use in adults. It is a novel agent with multiple potential mechanisms of action demonstrated in animal studies. Potential pharmacodynamic properties include attenuation of N-methyl-D-aspartate (NMDA) (Mayer et al. 2002; Naassila et al. 1998) and metabotropic type 5 glutamate receptor (mGluR5) (Blednov and Adron Harris 2008; Gupta et al. 2008; Harris et al. 2002; Kotlinska and Bochenski 2008) 
neurotransmission and agonist effects at gamma-aminobutyric acid type A (GABA(A)) neuroreceptors (Mann et al. 2008; Pierrefiche et al. 2004). The exact mechanisms of action of acamprosate remain unclear, in part, given results of an electrophysiology receptor binding study that noted no direct activity of acamprosate at glutamate or GABA receptors using clinically relevant drug concentrations (Reilly et al. 2008). Given excessive glutamatergic and deficient GABAergic neurotransmission have been noted in studies of humans with idiopathic ASD noted in idiopathic ASD (McDougle et al. 2005), the pharmacodynamic properties of acamprosate may be well matched with the pathophysiology of ASD. Also, acamprosate use in FXS-associated ASD is supported by extensive bodies of literature noting excessive mGluR5 (Bear 2005; Bear et al. 2004) and deficient GABA(A) (Bear 2005; Bear et al. 2004) neurotransmission in this disorder.

In a preliminary report, potential improvement in communication was described with openlabel acamprosate treatment in 3 adults with FXS and ASD (mean duration: 21.3 weeks; mean dose $=1,221 \mathrm{mg} /$ day) (Erickson et al. 2010). Subsequently, a 10-week prospective open-label trial of acamprosate (mean dose $=1,054 \pm 422 \mathrm{mg} /$ day) in 12 youth (mean age: 11.9 years) with FXS and comorbid ASD was completed (Erickson et al. 2013b). In this study, acamprosate was associated with positive clinical response in 9 subjects $(75 \%)$ with specific improvement noted in social impairment and inattention/hyperactivity (Erickson et al. 2013b).

In an open-label naturalistic study of acamprosate (mean duration: 20 weeks; mean dose= $1,110 \mathrm{mg} /$ day) in six youth with idiopathic autism (mean age: 9.5 years), the drug was associated with positive response in five subjects (83\%) with improvement primarily noted in social relatedness (Erickson et al. 2011). More recently, results from a single-blind, placebo lead-in pilot study of acamprosate in 12 youth with idiopathic ASD were reported. In this report, 6 of $9(67 \%)$ of youth with ASD who received acamprosate showed clinical response characterized by improvement in social relatedness and inattention/hyperactivity (Erickson et al. 2013a).

Given several factors, including the need to better understand the pharmacodynamic effects of acamprosate in ASD, the potential importance of APP dysregulation in the pathophysiology of ASD, and the need for quantitative biomarkers to predict and assess treatment response in clinical trials of ASD, we now report on the impact of acamprosate use on APP and its metabolites in youth with idiopathic and FXS-associated ASD. We hypothesized that acamprosate use would be associated with reductions in APP and its metabolites, specifically sAPPa, and that these changes would correlate with positive response to acamprosate.

\section{Materials and Methods}

Levels of total sAPP (total), sAPPa, A $\beta 40$, and A $\beta 42$ were analyzed from plasma specimens of subjects participating in a pilot 10-week open-label study of acamprosate in 12 youth aged 5-17 years with full mutation FXS and comorbid ASD (Erickson et al. 2013b) or in a pilot study in 12 youth aged 5-17 years with idiopathic autism who, following a 2-week placebo lead-in, received 10 weeks of single-blind acamprosate treatment (Erickson et al. 
2013a). For all subjects, two plasma samples were compared, baseline sampling prior to study drug treatment and sampling at final study visit. All subjects remained on stable concomitant psychotropic drug dosing throughout the pilot trials with the exception of use of modulators of glutamate or GABA(A) neurotransmission which were prohibited.

Blood samples were collected in tubes containing EDTA ( $\mathrm{K}_{2}$ EDTA from Becton Dickinson, Franklin Lakes, NJ, USA, product \#367863), Test plasma samples were prepared soon after collection. Briefly, plasma was isolated from freshly drawn blood by centrifuging at $1000 \times \mathrm{g}$ for 12 minutes. The isolated plasma samples were further centrifuged at $10,000 \times \mathrm{g}$ for 10 minutes for complete removal of platelets. Prepared plasma samples were aliquoted in several microfuge tubes and stored at $-80^{\circ} \mathrm{C}$ to avoid repeat freeze-th aw. The test samples were thawed on ice just before use. If necessary, the plasma samples were diluted appropriately with the EIA buffer, and the appropriate assay was performed in duplicate measurements for the test samples and standards. Test samples in neutral $\mathrm{pH}$ range were used, and steps were taken to avoid the contamination from organic solvents. Regarding the standard to quantify the sAPPa levels, a series of sAPPa standards were prepared in EIA buffer by serial dilutions from $0.78 \mathrm{ng} / \mathrm{mL}$ to $50 \mathrm{ng} / \mathrm{mL}$. Most of the procedure have recently been reported by us ${ }^{15}$.

The ELISA plates were pre-coated with highly specific anti-human affinity purified sAPPa (2B3) mouse IgG-monoclonal antibody (IBL America). First, the wells for the reagent blank were determined, and $100 \mu \mathrm{L}$ each of "EIA buffer" buffer was placed into the blank wells. Likewise, different wells were assigned for the test samples and diluted standards. Next, 100 $\mu \mathrm{L}$ each of test samples and dilutions of standards in EIA buffer were added into the appropriate wells. The test sample included the plasma sample from each subject, which may vary from 5-25 $\mu \mathrm{L}$. The pre-coated plate was incubated overnight at $4^{\circ} \mathrm{C}$. After several washes, $100 \mu \mathrm{L}$ of labeled antibody solution was added into the wells of test samples, diluted standard and of test sample blank. HRP-conjugated and labeled anti- Human APP (R101A4) mouse IgG from IBL was used. Each plate was incubated for 30 minutes at $4^{\circ} \mathrm{C}$ and then washed several times. ELISA signals were developed by adding TMB buffer followed by the addition of Stop buffer $1(\mathrm{~N}) \mathrm{H}_{2} \mathrm{SO}_{4}$. Using a plate reader (BioRad) measurements were conducted at $450 \mathrm{~nm}$ against a reagent blank. The measurement was done within 30 minutes addition of the Stop solution. Before performing the ELISA with all plasma samples, different volumes of a "pool" plasma sample were analyzed to establish the linearity of the assay.

To determine sAPP levels, we thawed the test samples at a low temperature and mixed them completely. Regarding the standard to quantify levels of sAPP, we prepared a series of sAPP standards in EIA buffer by serial dilutions, from $0.39 \mathrm{ng} / \mathrm{mL}$ to $25 \mathrm{ng} / \mathrm{mL}$. The ELISA plate was pre-coated with anti-human APP (R12A1) mouse IgG (IBL). ELISA of plasma samples was carried out as per the manufacturer's protocol and similar to the method described above. This ELISA kit uses HRP-labeled anti- Human APP (R101A4) mouse IgG as the detection antibody. Levels of $A \beta$ peptides were assayed in platelet free plasma samples by an ultra sensitive and specific ELISA (Wako Chemical Industries, Japan). Plasma samples were diluted 2-10 times to avoid nonspecific signals. The ELISAs use highly specific capture antibodies BA27 and BC05 to detect $\mathrm{A} \beta(1-40)$ and $\mathrm{A} \beta$ (1-42), respectively. The 
overall assay procedures were performed as per the guidelines of the manufacturer. ELISA of the plasma samples were performed in a 'blinded' manner.

The primary outcomes of this report are comparison of plasma levels of sAPP-total, sAPPa, $\mathrm{A} \beta 40, \mathrm{~A} \beta 42$, as well as the ratios of sAPPa/sAPP and A $\beta 42 / \mathrm{A} \beta 40$ pre- and postacamprosate treatment. All data were coded into IBM SPSS Statistics 21 or SAS 9.4 for analysis. The differences between pre- and post- assays were compared by paired t-tests in the pool sample (FXS and idiopathic ASD), by bootstrap resampling of the mean difference in the individual treatment groups and 95\% confidence intervals and Hedge's $g$ calculated. An exploratory Kendall's tau correlation analysis was conducted to assess for any relationship between change in primary outcomes above and change in behavioral outcome measures that showed improvement during our pilot clinical trials. This included analysis of the Social Responsiveness Scale (SRS) (Constantino et al. 2003) total score, Aberrant Behavior Checklist Social Withdrawal subscale (ABC-SW) (Aman et al. 1985), ADHD Rating Scale $4^{\text {th }}$ Edition (ADHD-RS) (DuPaul et al. 1998), and Clinical Global Impression Improvement (CGI-I) scale (Guy 1976).

Finally, we conducted an analysis of baseline APP plasma derivatives in youth with FXS and ASD versus age-, gender- and IQ-matched youth with idiopathic ASD. This sampling involved all subjects enrolled in the FXS pilot clinical trial of acamprosate (pre-treatment analysis) and a group of matched subjects with idiopathic ASD not receiving acamprosate or other glutamate or GABA(A) modulators. Samples were assayed for total soluble APP (sAPP-total), soluble APPa (sAPPa), A $\beta 42$, and A $\beta 40$. The ratios of sAPPa/sAPP and $\mathrm{A} \beta 42 / \mathrm{A} \beta 40$ were calculated. Bootstrap estimation of the differences between mean values of idiopathic ASD samples vs. FXS samples was done, instead, with $95 \%$ and $90 \%$ confidence intervals calculated. Those differences for which the confidence interval did not cross zero were counted as "significant" at $\mathrm{p}<0.05$ or $\mathrm{p}<0.10$, as appropriate. In addition, Hedge's $g$ standardized effect sizes were calculated for each marker or ratio.

\section{Results}

Fifteen subjects (mean age: 11.1 years, range 6-15 years; mean IQ= 55, range 47-83) had available pre- and post-acamprosate plasma sAPP derivative levels (see Table 1). This sample included 9 youth with FXS-associated ASD (mean age: 10.9 years) and 6 youth with idiopathic ASD (mean age: 11.4 years). Thirteen subjects received concomitant psychotropic drugs (mean number of drugs $=1.9$ ) at stable doses during the trial period (see Table 2). The mean final acamprosate dose for subjects in this analysis was $1,061 \mathrm{mg} / \mathrm{day}$. Acamprosate treatment significantly $(\mathrm{p}<0.05)$ reduced levels of overall sAPP-total and sAPPa in both subjects with FXS-associated or idiopathic ASD in the pooled sample and divided by treatment group (FXS versus idiopathic ASD; Tables 3-4; Figure 1).

Acamprosate treatment also increased the sAPPa/sAPP ratio in both groups. However, several of the markers measured appeared to have a single large outlier. A crude validation was done by leaving out the most extreme individual difference of each marker or ratio and repeating the analysis. When this was done, the reductions in SAPP and SAPPa were maintained. The increase in the mean sAPPa/sAPP ratio following acamprosate treatment lost significance in the idiopathic ASD group. On the other hand, this produced a significant 
result for reduced $\mathrm{A} \beta 42$ levels in the FXS-associated ASD group. These results suggest that acamprosate treatment reduces overall sAPP levels in both FXS-associated ASD and idiopathic ASD, and that this may be accompanied by a somewhat greater redirection toward the a-secretase processing pathway in FXS-associated than in idiopathic ASD.

Our exploratory Kendall's tau correlation analysis noted no correlation between change in plasma sAPP-total, sAPPa, A $\beta 40$, or A $\beta 42$ and change on the SRS, ABC-SW, ADHD-RS, or CGI-I in the pooled patient sample $(n=15)$. In the FXS-associated $(n=9)$ subgroup, change in ABC-SW scores correlated with change in sAPP-total $(\mathrm{p}=0.009)$ and $\mathrm{sAPPa}(\mathrm{p}=0.04)$. No significant correlations were noted in the idiopathic ASD $(n=6)$ subgroup.

In our comparison of baseline plasma APP derivatives between youth with FXS- associated ASD ( $n=12$; mean age: 11.9 years) versus those with idiopathic ASD ( $n=11$, mean age: 11.8 years; see Tables 5-6), all individual markers analyzed had higher levels in the FXSassociated ASD group (Table 7; Figure 2). This was also true for the sAPPa/sAPP ratio. Of the differences, only sAPPa/sAPP was significant at $\mathrm{p}<0.05$, suggesting that youth with FXS-associated ASD have greater levels of pro-neurotropic sAPPa species than those with idiopathic ASD. Levels of A $\beta 42$ were higher in FXS-associated ASD at $p<0.10$. A $\beta 40$ was also higher in FXS-associated versus idiopathic ASD, although the difference was not significant. Overall, there was a tendency toward greater APP-related protein and peptide products in plasma of youth with FXS-associated ASD. Crude validation was done by repeating the analysis while excluding the most extreme value for each marker or ratio within the FXS and idiopathic autism samples. When this was done, the difference between FXS-associated and idiopathic ASD for A $\beta 42$ levels was accompanied by significance of $p$ $<0.05$ instead of $\mathrm{p}<0.10$. On the other hand, the difference for sAPPa/sAPP lost significance of $p<0.05$, but remained within $p<0.10$. Thus, our conclusions should be taken with some caution, but permitting the possibility of better resolution in a larger study.

\section{Discussion}

This is the first report on potential change in plasma proteins sAPP-total and sAPPa, and peptides $A \beta 40$, and $A \beta 42$ following drug treatment in youth with ASD. Due to inaccessibility of brain tissue samples from living subjects, we have argued recently that the plasma levels of these "neuronal" proteins would reflect the change occurring in the CNS (Ray et al. 2011; Sokol et al. 2011). Given the implication of APP dysregulation in the pathophysiology of ASD, it will be important to consider in particular elevations of sAPPa as a measurable target of treatment of the disorder. Baseline profiling of plasma APP derivatives may also hold promise in molecular endophenotyping as a means to potentially predict targeted treatment response in future ASD clinical trials.

We additionally reported on novel comparison of sAPP derivative plasma levels in youth with FXS-associated or idiopathic ASD matched on age, IQ, and gender. This comparison controlled for the diagnosis of ASD to see if differences in the APP processing pathway may exist due to FXS. Our initial data points towards increased pro-neurotrophic sAPPa in FXSassociated versus idiopathic ASD. Without a neurotypical control group in this report, further interpretation is limited. Despite this, our findings may represent, based on extension 
from previously reported data (Bailey et al. 2008; Ray et al. 2011; Sokol et al. 2006; Sokol et al. 2011), a continuum of excessive non-amyloidogenic APP processing where both FXSassociated and idiopathic ASD show a non-amyloidogenic processing bias compared to controls, with FXS being potentially associated with the greatest non-amyloidogenic processing bias.

The reduction in total sAPP and sAPPa levels independently with acamprosate treatment takes an important step in understanding the potential molecular mechanisms of this drug in persons with ASD. This is of particular importance given the implication of specifically excessive sAPPa production in persons with ASD. This work begins to demonstrate engagement of a novel drug treatment with a putative molecular marker of pathophysiology in a disorder devoid of validated biomarkers for use in clinical trials. The specific mechanisms by which acamprosate may lead to reduction in total sAPP and sAPPa remain to be understood. Our hypothesis is that potentially direct or indirect attenuation of glutamate receptor, specifically mGluR5, activity may lead to reengagement of a transcriptional break on APP production given preclinical reports describing control of APP translation in FXS animal models.

The results of this work must be taken in the context of the multiple limitations of the study design. Our primary limitation is the sample size with pre- and post-acamprosate sampling from only 15 study subjects. Given this, our ability to detect more subtle drug effects and/or begin to understand correlations between change in sAPPtotal, sAPPa, A $\beta 40$, or A $\beta 42$ and change in behavioral outcome measures is very limited. Our lack of a positive correlation finding of APP derivative change and outcome measure findings may be due to this weakness. Additionally, while the APP analysis was conducted blinded to study assignment, the open-label nature of the drug trials introduced bias into the behavioral outcome assessments thus further confounding our correlation analysis.

The use of concomitant psychotropic drugs at stable doses may potentially alter baseline APP derivative levels thus obscuring the ability to detect change with acamprosate treatment. For example, rivastigmine has been demonstrated to lower $\mathrm{A} \beta$ and increase sAPPa levels (Bailey et al. 2011). Despite these limitations, a clear signal of significant reduction in plasma sAPPtotal and sAPPa levels following acamprosate treatment was noted. Inexact matching in baseline medication use may have also impacted our APP derivative comparisons between youth with FXS-associated and idiopathic ASD. Despite this, our overall patterns of concomitant medication use were quite similar among groups (see Table 5). Future placebo-controlled study potentially stratifying based on concomitant medication use patterns or study prohibiting concomitant medications will be necessary to fully understand this issue.

Our use of plasma measurement essentially as a proxy for what may occur within the brain is a potential weakness of our analysis. We recognize the fact that it would be difficult to have a direct correlation between plasma and brain levels of APP metabolites due to, among other factors, differences in the PD and PK profile of the drug tested in different tissues. There are very few reports of parallel measurements of proteins and other molecules in both plasma and brain tissue samples(Tajima et al. 2013). There is an interesting report of an in 
vivo evaluation of avagacestat (a $\gamma$-secretase inhibitor) in dogs, which showed a plasma halflife that supports daily oral dosing, good brain penetration, and a correlation between reductions of $A \beta 40$ levels in the brain and cerebrospinal fluid (CSF)(Albright et al. 2013).

Future directions based upon our findings include use of plasma APP derivative analysis both in larger samples of persons with FXS-associated and idiopathic ASD receiving acamprosate and following use of other potential novel targeted treatments. Currently, we are analyzing plasma levels of sAPPtotal, sAPPa, A $\beta 40$, and A $\beta 42$ pre- and post-treatment in placebo-controlled trials of acamprosate in new cohorts of youth with idiopathic ASD (NCT01813318) or FXS (NCT01911455). It will also be important to consider future preclinical methods to parse out what specific drug mechanisms may reduce plasma sAPPtotal and sAPPa Given the uncertainty surrounding the mechanisms of acamprosate and the likely multiple mechanisms of action of this drug, an improved mechanistic understanding of the pharmacodynamic property(s) necessary to modulate APP derivatives in these populations will be essential to future targeted treatment developments.

\section{Acknowledgments}

We sincerely appreciate the grant supports from the Autism Speaks, Cincinnati Children's Hospital, Alzheimer's Association (IIRG) and NIA/National Institutes of Health.

This work was supported by grants from National Institutes of Health (NIA-R01 and -R21) and Alzheimer's Association (IIRG) to DKL, and from the Indiana CTSI to CE and DKL and from the American Academy of Child and Adolescent Psychiatry to CE.

Role of Funding Source: The funding sources noted in the Acknowledgement section had no role in study design, in the collection, analysis, and interpretation of data, in the writing of the report, or in the decision to submit the article for publication.

\section{References}

Albright CF, et al. Pharmacodynamics of selective inhibition of gamma-secretase by avagacestat. J Pharmacol Exp Ther. 2013; 344:686-95.10.1124/jpet.112.199356 [PubMed: 23275065]

Alley GM, Bailey JA, Chen D, Ray B, Puli LK, Tanila H, Banerjee PK, Lahiri DK. Memantine lowers amyloid-beta peptide levels in neuronal cultures and in APP/PS1 transgenic mice. J Neurosci Res. 2010; 88(1):143-54. [PubMed: 19642202]

Aman MG, Singh NN, Stewart AW, Field CJ. The Aberrant Behavior Checklist: a behavior rating scale for the assessment of treatment effects. American Journal of Mental Deficiency. 1985; 5:485491. [PubMed: 3993694]

American_Psychiatric_Association. Diagnostic and Statistical Manual of Mental Disorders. Four Text Revision. Washington, D.C.: American Psychiatric Association; 2000.

American_Psychiatric_Association. DSM-5. 5th. Washington, D.C.: American Psychiatric Publishing; 2013. Diagnostic and Statistical Manual.

Aylward EH, Minshew NJ, Field K, Sparks BF, Singh N. Effects of age on brain volume and head circumference in autism. Neurology. 2002; 59:175-83. [PubMed: 12136053]

Aylward EH, et al. MRI volumes of amygdala and hippocampus in non-mentally retarded autistic adolescents and adults. Neurology. 1999; 53:2145-50. [PubMed: 10599796]

Bagni C, Greenough WT. From mRNP trafficking to spine dysmorphogenesis: the roots of fragile X syndrome. Nature reviews Neuroscience. 2005; 6:376-87. doi:nrn1667 [pii] 10.1038/nrn1667 [doi].

Bailey AR, et al. Peripheral biomarkers in Autism: secreted amyloid precursor protein-alpha as a probable key player in early diagnosis. Int J Clin Exp Med. 2008; 1:338-44. [PubMed: 19079679] 
Bailey JA, Ray B, Greig NH, Lahiri DK. Rivastigmine lowers Abeta and increases sAPPalpha levels, which parallel elevated synaptic markers and metabolic activity in degenerating primary rat neurons. PLoS One. 2011; 6:e21954.10.1371/journal.pone.0021954 [PubMed: 21799757]

Barger SW, Harmon AD. Microglial activation by Alzheimer amyloid precursor protein and modulation by apolipoprotein E. Nature. 1997; 388:878-81.10.1038/42257 [PubMed: 9278049]

Bear MF. Therapeutic implications of the mGluR theory of fragile X mental retardation. Genes Brain Behav. 2005; 4:393-8. doi:GBB135 [pii] 10.1111/j.1601-183X.2005.00135.x [doi]. [PubMed: 16098137]

Bear MF, Huber KM, Warren ST. The mGluR theory of fragile X mental retardation. Trends Neurosci. 2004; 27:370-7. doi:10.1016/j.tins.2004.04.009 [doi] S0166223604001328 [pii]. [PubMed: 15219735]

Blednov YA, Adron Harris R. Metabotropic glutamate receptor 5 (mGluR5) regulation of ethanol sedation, dependence and consumption: relationship to acamprosate actions. Int J Neuropsychopharmacol. 2008; 11:775-93. doi:S1461145708008584 [pii] 10.1017/ S1461145708008584 [doi]. [PubMed: 18377703]

Clifford S, Dissanayake C, Bui QM, Huggins R, Taylor AK, Loesch DZ. Autism spectrum phenotype in males and females with fragile $\mathrm{X}$ full mutation and premutation. J Autism Dev Disord. 2007; 37:738-47. doi:10.1007/s10803-006-0205-z [doi]. [PubMed: 17031449]

Constantino JN, et al. Validation of a brief quantitative measure of autistic traits: comparison of the social responsiveness scale with the autism diagnostic interview-revised. J Autism Dev Disord. 2003; 33:427-33. [PubMed: 12959421]

Courchesne E, Carper R, Akshoomoff N. Evidence of brain overgrowth in the first year of life in autism. JAMA. 2003; 290:337-44. doi:10.1001/jama.290.3.337 290/3/337 [pii]. [PubMed: 12865374]

Courchesne E, et al. Unusual brain growth patterns in early life in patients with autistic disorder: an MRI study. Neurology. 2001; 57:245-54. [PubMed: 11468308]

Courchesne E, Pierce K. Brain overgrowth in autism during a critical time in development: implications for frontal pyramidal neuron and interneuron development and connectivity. Int J Dev Neurosci. 2005; 23:153-70. doi:S0736-5748(05)00004-3 [pii] 10.1016/j.ijdevneu.2005.01.003. [PubMed: 15749242]

Darnell JC, et al. FMRP stalls ribosomal translocation on mRNAs linked to synaptic function and autism. Cell. 2011; 146:247-61.10.1016/j.cell.2011.06.013 [PubMed: 21784246]

Davidovitch M, Patterson B, Gartside P. Head circumference measurements in children with autism. J Child Neurol. 1996; 11:389-93. [PubMed: 8877607]

De Rubeis S, Bagni C. Fragile X mental retardation protein control of neuronal mRNA metabolism: Insights into mRNA stability. Mol Cell Neurosci. 2010; 43:43-50. doi:S1044-7431(09)00219-X [pii] 10.1016/j.mcn.2009.09.013. [PubMed: 19837168]

DuPaul, G.; Power, T.; Anastopaulus, A.; Reid, R. ADHD Rating Scale IV: Checklists, Norms, and Clinical Interpretation. New York: Guilford; 1998.

Erickson CA, Early M, Stigler KA, Wink LK, Mullett JE, McDougle CJ. An open-label naturalistic pilot study of acamprosate in youth with autistic disorder. Journal of child and adolescent psychopharmacology. 2011; 21:565-9.10.1089/cap.2011.0034 [PubMed: 22136091]

Erickson CA, Mullett JE, McDougle CJ. Brief report: acamprosate in fragile X syndrome. Journal of autism and developmental disorders. 2010; 40:1412-6.10.1007/s10803-010-0988-9 [PubMed: 20213249]

Erickson CA, et al. Brief Report: Pilot Single-Blind Placebo Lead-In Study of Acamprosate in Youth with Autistic Disorder. J Autism Dev Disord. 2013a10.1007/s10803-013-1943-3

Erickson CA, et al. Impact of acamprosate on behavior and brain-derived neurotrophic factor: an openlabel study in youth with fragile X syndrome. Psychopharmacology. 2013b10.1007/ s00213-013-3022-z

Fatemi SH, Folsom TD, Kneeland RE, Yousefi MK, Liesch SB, Thuras PD. Impairment of fragile X mental retardation protein-metabotropic glutamate receptor 5 signaling and its downstream cognates ras-related $\mathrm{C} 3$ botulinum toxin substrate 1, amyloid beta A4 precursor protein, striatalenriched protein tyrosine phosphatase, and homer 1, in autism: a postmortem study in cerebellar 
vermis and superior frontal cortex. Mol Autism. 2013; 4:21.10.1186/2040-2392-4-21 [PubMed: 23803181]

Garcia-Nonell C, et al. Secondary medical diagnosis in fragile X syndrome with and without autism spectrum disorder. Am J Med Genet A. 2008; 146A:1911-6. doi:10.1002/ajmg.a.32290 [doi]. [PubMed: 18627038]

Greig NH, et al. Selective butyrylcholinesterase inhibition elevates brain acetylcholine, augments learning and lowers Alzheimer beta-amyloid peptide in rodent. Proc Natl Acad Sci U S A. 2005; 102:17213-8.10.1073/pnas.0508575102 [PubMed: 16275899]

Gupta T, et al. Acute effects of acamprosate and MPEP on ethanol Drinking-in-the-Dark in male C57BL/6J mice. Alcohol Clin Exp Res. 2008; 32:1992-8. doi:ACER787 [pii] 10.1111/j. 1530-0277.2008.00787.x [doi]. [PubMed: 18782337]

Guy, W. ECDEU assessment manual for psychopharmacology, Publication No 76-338. Washington, DC: U.S. DHEW, NIMH; 1976.

Harris BR, et al. Acamprosate inhibits the binding and neurotoxic effects of trans-ACPD, suggesting a novel site of action at metabotropic glutamate receptors. Alcohol Clin Exp Res. 2002; 26:1779-93. doi:10.1097/01.ALC.0000042011.99580.98 [doi]. [PubMed: 12500101]

Hatton DD, et al. Autistic behavior in children with fragile X syndrome: prevalence, stability, and the impact of FMRP. Am J Med Genet A. 2006; 140A:1804-13. doi:10.1002/ajmg.a.31286 [doi]. [PubMed: 16700053]

Hazlett HC, et al. Early brain overgrowth in autism associated with an increase in cortical surface area before age 2 years. Arch Gen Psychiatry. 2011; 68:467-76.10.1001/archgenpsychiatry.2011.39 [PubMed: 21536976]

Hazlett HC, et al. Trajectories of early brain volume development in fragile X syndrome and autism. J Am Acad Child Adolesc Psychiatry. 2012; 51:921-33.10.1016/j.jaac.2012.07.003 [PubMed: 22917205]

Jolly-Tornetta C, Gao ZY, Lee VM, Wolf BA. Regulation of amyloid precursor protein secretion by glutamate receptors in human Ntera 2 neurons. J Biol Chem. 1998; 273:14015-21. [PubMed: 9593752]

Kaufmann WE, et al. Autism spectrum disorder in fragile X syndrome: communication, social interaction, and specific behaviors. Am J Med Genet A. 2004; 129A:225-34. doi:10.1002/ajmg.a. 30229 [doi]. [PubMed: 15326621]

Kosinovsky B, et al. The yield of laboratory investigations in children with infantile autism. J Neural Transm. 2005; 112:587-96. doi:10.1007/s00702-004-0198-8 [doi]. [PubMed: 15503196]

Kotlinska J, Bochenski M. The influence of various glutamate receptors antagonists on anxietylike effect of ethanol withdrawal in a plus-maze test in rats. Eur J Pharmacol. 2008; 598:57-63. doi:S0014-2999(08)00970-9 [pii] 10.1016/j.ejphar.2008.09.026 [doi]. [PubMed: 18838071]

Lahiri DK, Farlow MR, Sambamurti K. The secretion of amyloid beta-peptides is inhibited in the tacrine-treated human neuroblastoma cells. Brain Res Mol Brain Res. 1998; 62:131-40. [PubMed: 9813282]

Lahiri DK, Farlow MR, Sambamurti K, Greig NH, Giacobini E, Schneider LS. A critical analysis of new molecular targets and strategies for drug developments in Alzheimer's disease. Current drug targets. 2003; 4:97-112. [PubMed: 12558063]

Lahiri DK, Lewis S, Farlow MR. Tacrine alters the secretion of the beta-amyloid precursor protein in cell lines. J Neurosci Res. 1994; 37:777-87.10.1002/jnr.490370612 [PubMed: 8046778]

Lahiri, DK.; Long, JM.; Ray, B.; Sokol, DK. Biochemical Evidence for the Dysregulation of Alzheimer's Amyloid Precursor Protein (APP) Expression and Metabolism in Fragile X Syndrome (FXS) and Severe Autism; Paper presented at the Society of Biological Psychiatry; New Orleans, Louisiana. May 12,2011; 2011.

Lahiri DK, Maloney B, Long JM, Greig NH. Lessons from a BACE1 inhibitor trial: Off-site but not off base. Alzheimers Dement. 2014; S1552-5260(13):02917-8. 2014.

Lahiri DK, Nall C, Chen D, Zaphiriou M, Morgan C, Nurnberger JI Sr. Developmental expression of the beta-amyloid precursor protein and heat-shock protein 70 in the cerebral hemisphere region of the rat brain. Ann N Y Acad Sci. 2002; 965:324-333. [PubMed: 12105108] 
Lahiri DK, Sokol DK, Erickson C, Ray B, Ho CY, Maloney B. Autism as early neurodevelopmental disorder: evidence for an sAPPalpha-mediated anabolic pathway. Front Cell Neurosci. 2013; 7:94.10.3389/fncel.2013.00094 [PubMed: 23801940]

Lee EK, et al. hnRNP C promotes APP translation by competing with FMRP for APP mRNA recruitment to $\mathrm{P}$ bodies. Nature structural \& molecular biology. 2010; 17:732-9.10.1038/nsmb. 1815

Mann K, Kiefer F, Spanagel R, Littleton J. Acamprosate: recent findings and future research directions. Alcohol Clin Exp Res. 2008; 32:1105-10. doi:ACER690 [pii] 10.1111/j. 1530-0277.2008.00690.x [doi]. [PubMed: 18540918]

Mattson MP. Secreted forms of beta-amyloid precursor protein modulate dendrite outgrowth and calcium responses to glutamate in cultured embryonic hippocampal neurons. J Neurobiol. 1994; 25:439-50.10.1002/neu.480250409 [PubMed: 7915758]

Mattson MP. Cellular actions of beta-amyloid precursor protein and its soluble and fibrillogenic derivatives. Physiol Rev. 1997; 77:1081-132. [PubMed: 9354812]

Mattson MP, Furukawa K. Signaling events regulating the neurodevelopmental triad. Glutamate and secreted forms of beta-amyloid precursor protein as examples. Perspect Dev Neurobiol. 1998; 5:337-52. [PubMed: 10533524]

Mayer S, et al. Acamprosate has no effect on NMDA-induced toxicity but reduces toxicity induced by spermidine or by changing the medium in organotypic hippocampal slice cultures from rat. Alcohol Clin Exp Res. 2002; 26:655-62. [PubMed: 12045473]

McCaffery P, Deutsch CK. Macrocephaly and the control of brain growth in autistic disorders. Progress in neurobiology. 2005; 77:38-56. doi:S0301-0082(05)00118-8 [pii] 10.1016/j.pneurobio. 2005.10.005. [PubMed: 16280193]

McDougle CJ, Erickson CA, Stigler KA, Posey DJ. Neurochemistry in the pathophysiology of autism. J Clin Psychiatry. 2005; 66(Suppl 10):9-18. [PubMed: 16401145]

McGrew SG, Peters BR, Crittendon JA, Veenstra-Vanderweele J. Diagnostic yield of chromosomal microarray analysis in an autism primary care practice: which guidelines to implement? J Autism Dev Disord. 2012; 42:1582-91.10.1007/s10803-011-1398-3 [PubMed: 22089167]

Mullan M, Crawford F. Genetic and molecular advances in Alzheimer's disease. Trends Neurosci. 1993; 16:398-403. [PubMed: 7504354]

Naassila M, Hammoumi S, Legrand E, Durbin P, Daoust M. Mechanism of action of acamprosate. Part I. Characterization of spermidine-sensitive acamprosate binding site in rat brain. Alcohol Clin Exp Res. 1998; 22:802-9. doi:00000374-199806000-00005 [pii]. [PubMed: 9660304]

Pierrefiche O, Daoust M, Naassila M. Biphasic effect of acamprosate on NMDA but not on GABAA receptors in spontaneous rhythmic activity from the isolated neonatal rat respiratory network. Neuropharmacology. 2004; 47:35-45. doi:10.1016/j.neuropharm.2004.03.004 S002839080400070X [pii]. [PubMed: 15165832]

Priller C, Bauer T, Mitteregger G, Krebs B, Kretzschmar HA, Herms J. Synapse formation and function is modulated by the amyloid precursor protein. J Neurosci. 2006; 26:7212-21. doi: 26/27/7212 [pii] 10.1523/JNEUROSCI.1450-06.2006. [PubMed: 16822978]

Ray B, Long JM, Sokol DK, Lahiri DK. Increased secreted amyloid precursor protein-alpha (sAPPalpha) in severe autism: proposal of a specific, anabolic pathway and putative biomarker. PLoS One. 2011; 6:e20405.10.1371/journal.pone.0020405 [PubMed: 21731612]

Reilly MT, et al. Effects of acamprosate on neuronal receptors and ion channels expressed in Xenopus oocytes. Alcohol Clin Exp Res. 2008; 32:188-96. doi:ACER569 [pii] 10.1111/j. 1530-0277.2007.00569.x [doi]. [PubMed: 18226119]

Schubert D, Jin LW, Saitoh T, Cole G. The regulation of amyloid beta protein precursor secretion and its modulatory role in cell adhesion. Neuron. 1989; 3:689-94. doi:0896-6273(89)90237-7 [pii]. [PubMed: 2518372]

Sokol DK, et al. High levels of Alzheimer beta-amyloid precursor protein (APP) in children with severely autistic behavior and aggression. J Child Neurol. 2006; 21:444-9. [PubMed: 16948926]

Sokol DK, Maloney B, Long JM, Ray B, Lahiri DK. Autism, Alzheimer disease, and fragile X: APP, FMRP, and mGluR5 are molecular links. Neurology. 2011; 76:1344-52.10.1212/WNL. 0b013e3182166dc7 [PubMed: 21482951] 
Sparks BF. Brain structural abnormalities in young children with autism spectrum disorder. Neurology. 2002; 59:184-92. [PubMed: 12136055]

Stein TD, Johnson JA. Genetic programming by the proteolytic fragments of the amyloid precursor protein: somewhere between confusion and clarity. Rev Neurosci. 2003; 14:317-41. [PubMed: 14640319]

Tajima Y, et al. Lipidomic analysis of brain tissues and plasma in a mouse model expressing mutated human amyloid precursor protein/tau for Alzheimer's disease. Lipids in health and disease. 2013; 12:68.10.1186/1476-511X-12-68 [PubMed: 23659495]

Turner PR, O'Connor K, Tate WP, Abraham WC. Roles of amyloid precursor protein and its fragments in regulating neural activity, plasticity and memory. Progress in neurobiology. 2003; 70:1-32. [PubMed: 12927332]

Veneri M, Zalfa F, Bagni C. FMRP and its target RNAs fishing for the specificity. Neuroreport. 2004; 15:2447-50. doi:00001756-200411150-00002 [pii]. [PubMed: 15538171]

Wegiel J, et al. Abnormal intracellular accumulation and extracellular Abeta deposition in idiopathic and Dup15q11.2-q13 autism spectrum disorders. PLoS One. 2012; 7:e35414.10.1371/ journal.pone.0035414 [PubMed: 22567102]

Westmark CJ, Malter JS. FMRP mediates mGluR5-dependent translation of amyloid precursor protein. PLoS Biol. 2007; 5:e52. doi:1544-9173-5-3-e52 [pii] 10.1371/journal.pbio.0050052 [doi]. [PubMed: 17298186]

Westmark CJ, et al. Reversal of fragile X phenotypes by manipulation of AbetaPP/Abeta levels in Fmr1KO mice. PLoS One. 2011; 6:e26549.10.1371/journal.pone.0026549 [PubMed: 22046307]

Young-Pearse TL, Bai J, Chang R, Zheng JB, LoTurco JJ, Selkoe DJ. A critical function for betaamyloid precursor protein in neuronal migration revealed by in utero RNA interference. $\mathrm{J}$ Neurosci. 2007; 27:14459-69. [PubMed: 18160654]

Zalfa F, et al. The fragile X syndrome protein FMRP associates with BC1 RNA and regulates the translation of specific mRNAs at synapses. Cell. 2003; 112:317-27. doi:S0092867403000795 [pii]. [PubMed: 12581522]

Zou K, et al. Identification of FMRP-associated mRNAs using yeast three-hybrid system. Am J Med Genet B Neuropsychiatr Genet. 2008; 147B:769-77. doi:10.1002/ajmg.b.30678 [doi]. [PubMed: 18163424] 


\section{Highlights}

- This is the first report on use of plasma amyloid- $\beta$ precursor protein (APP) analysis pre- and post-targeted treatment in fragile $\mathrm{X}$-associated and idiopathic autism spectrum disorder.

- Acamprosate use was associated with uniform reduction in plasma sAPP (total) and sAPPa levels.

- Targeting elevated plasma sAPP (total) and sAPPa holds promise as a molecular target of treatment in fragile X-associated and idiopathic autism spectrum disorder. 


\section{Pre- and Post-Acamprosate in Idiopathic ASD Subject}
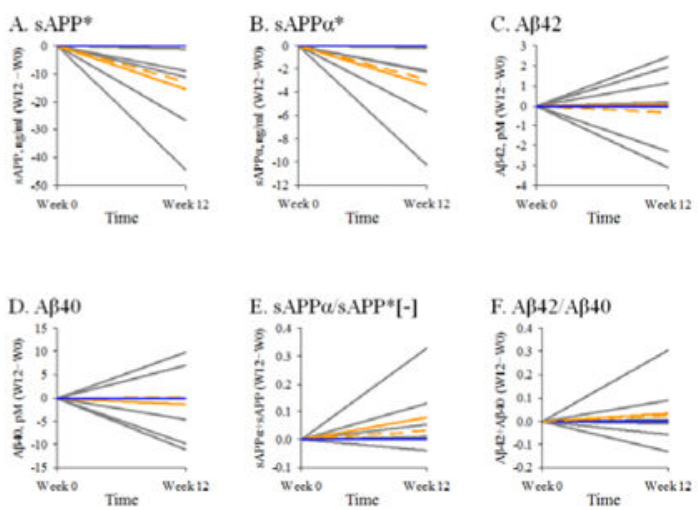

\section{Pre- and Post-Acamprosate in FXS Subjects}
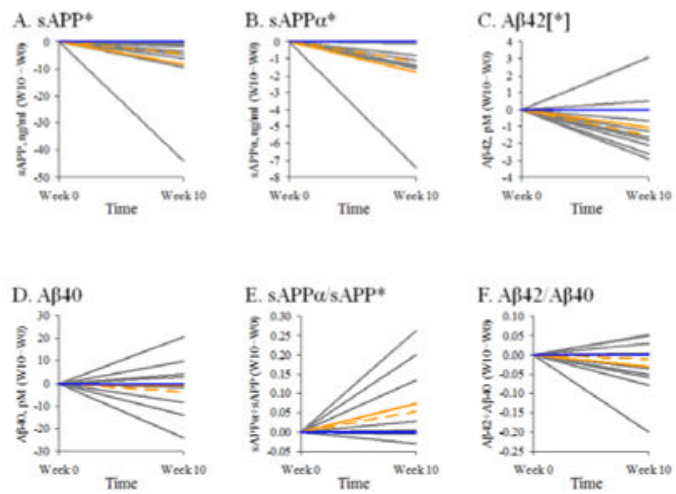

Fig. 1. Individual Subject Pre- and Post-Acamprosate Change Effects of acamprosate treatment of idiopathic autistic subjects on selected plasma

APP processing products. Six idiopathic autism subjects were treated with acamprosate as described in the text. Plasma samples were taken on day 0 (W0) and after 12 weeks (W12) and assayed for sAPPa, sAPP, A $\beta 42$, and A $\beta 40$. The W0 result for each individual subject was subtracted from its corresponding W12 result, and mean results subject to bootstrap analysis against the null hypothesis that W12 - W0 = 0. Results are presented as "fan plots", which explicitly link individual W12 to corresponding W0 results. Gray lines show individual subjects. Orange solid lines show mean sample change. Orange dashed lines show mean sample change excluding most extreme result. Blue lines show "null” zero. Figure includes results for A) sAPP, B) sAPPa, C) A $\beta 42$, D) A $\beta 40$, and E) A $\beta 42 / A \beta 40$. Samples significant at $\mathrm{p}<0.05$ are shown with “*”, those significant at $\mathrm{p}<0.10$ with " $\dagger$ ". If validation suggested a potential different level of significance, it is shown in square brackets "[]". 


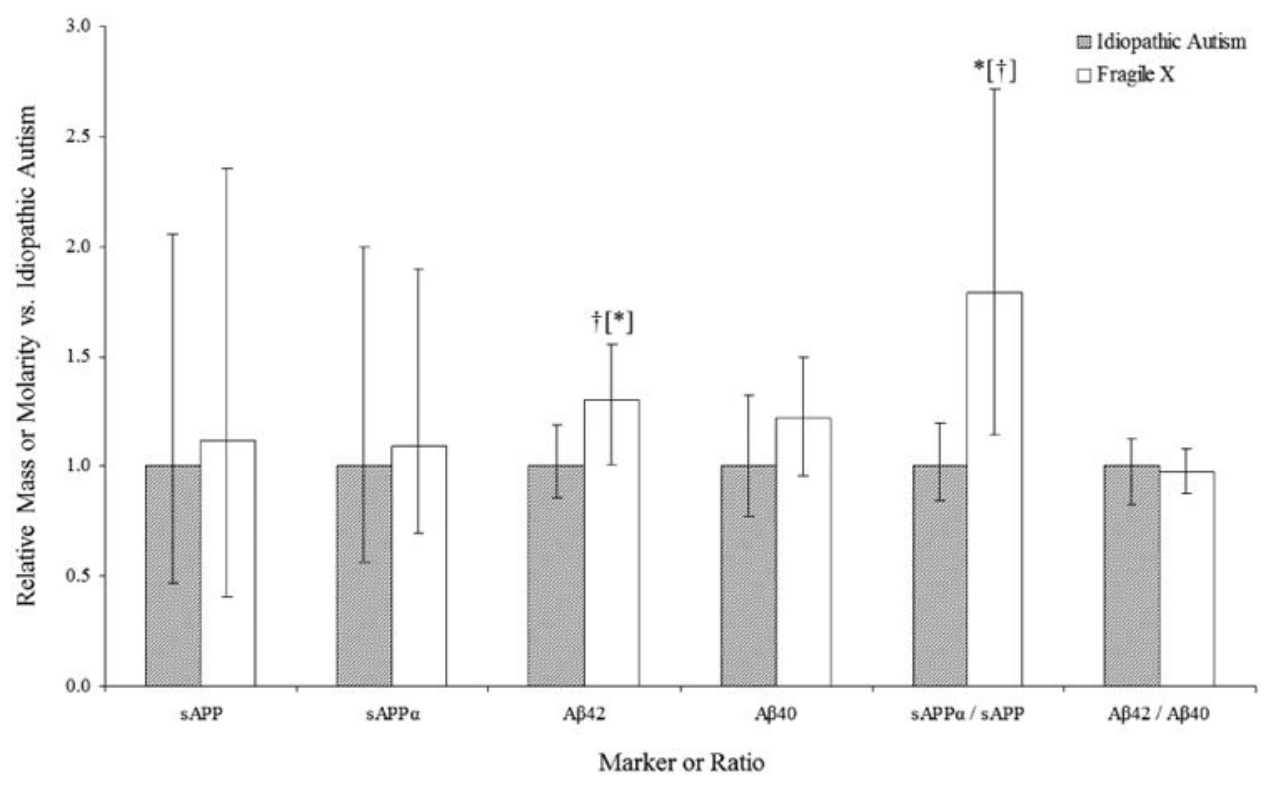

Fig. 2. Analysis of APP Derivatives in FXS-Associated Versus Idiopathic ASD Comparison of selected plasma APP processing products in idiopathic autism and fragile X. Plasma samples were collected from 11 idiopathic autism and 12 fragile $X$ subjects and assayed for sAPPa, sAPP, A $\beta 42$, and A $\beta 40$, as described in the text. Difference of means between autism and fragile $\mathrm{X}$ were analyzed by bootstrap. Relative mean values (idiopathic autism =1), with 95\% confidence interval error bars are shown. Samples significant at $\mathrm{p}<0.05$ are shown with “*”, those significant at $\mathrm{p}<0.10$ with " $\dagger$ ". If validation suggested a potential different level of significance, it is shown in square brackets "[]". 
Table 1

Characterization of Subjects for Pre- and Post-Acamprosate Treatment Analysis

\begin{tabular}{|l|l|l|l|l|}
\hline Group & Number of Male Subjects & Number of Female Subjects & Mean IQ & Mean Age (years) \\
\hline Idiopathic ASD & 5 & 1 & 72 & 11.4 \\
\hline FXS plus ASD & 7 & 2 & 45 & 10.9 \\
\hline
\end{tabular}


Table 2

Pre- and Post-Acamprosate Treatment Group Concomitant Psychotropic Medication Use

\begin{tabular}{|l|l|}
\hline Drug & Number of Subjects \\
\hline Risperidone & 6 \\
\hline Clonidine & 6 \\
\hline Fluoxetine & 3 \\
\hline Methylphenidate ER & 3 \\
\hline Aripiprazole & 2 \\
\hline Mirtazapine & 2 \\
\hline Guanfacine & 2 \\
\hline Vyvanse & 1 \\
\hline Trazodone & 1 \\
\hline Valproic Acid & 1 \\
\hline Dexedrine & 1 \\
\hline Oxcarbazepine & 1 \\
\hline
\end{tabular}


Table 3

Pre- and Post-Acamprosate Amyloid Precursor Protein Derivative Levels (pooled sample)

\begin{tabular}{|l|l|l|l|l|}
\hline Plasma Levels & APP Total $(\mathrm{ng} / \mathrm{mL})$ & sAPPa $(\mathrm{ng} / \mathrm{mL})$ & A $\beta 40(\mathrm{pg} / \mathrm{mL})$ & A $\beta 42(\mathrm{pg} / \mathrm{mL})$ \\
\hline Baseline $( \pm$ SEM $)$ & $32.60 \pm 9.90$ & $8.35 \pm 2.05$ & $144.67 \pm \mathbf{1 5 . 0 4}$ & $35.21 \pm 3.49$ \\
\hline Follow-up $( \pm$ SEM) & $21.45 \pm 8.34$ & $5.49 \pm 1.87$ & $138.70 \pm 11.13$ & $32.22 \pm 2.99$ \\
\hline P value (Paired T Test) & $\mathbf{0 . 0 1}$ & $\mathbf{0 . 0 0 3}$ & $\mathbf{0 . 6 4}$ & $\mathbf{0 . 2 7}$ \\
\hline
\end{tabular}

* Difference is significant at $\mathrm{p}<0.05$ 
Table 4

Acamprosate Treatment Effects on Plasma APP Processing Products in Idiopathic ASD vs. Fragile X Syndrome Associated ASD

\begin{tabular}{l|r|c|r|r}
\hline Marker & \multicolumn{2}{|c|}{$\begin{array}{r}\text { Idiopathic ASD } \\
\text { Difference }\end{array}$} & Hedge's $g$ & \multicolumn{2}{c}{ Fragile X Syndrome } \\
& Difference & Hedge's $g$ \\
\hline sAPP & $-13.05 \pm 7.65 / 18.34^{a}$ & $0.61 \pm 0.66 / 0.23$ & $-8.28 \pm 5.12 / 15.24^{a}$ & $0.55 \pm 0.20 / 0.20$ \\
sAPPa & $-2.94 \pm 1.81 / 4.43^{a}$ & $0.59 \pm 0.64 / 0.22$ & $-1.78 \pm 0.82 / 2.28^{a}$ & $0.75 \pm 0.25 / 0.31$ \\
A $\beta 42$ & $0.52 \pm 0.95 / 2.40$ & $0.20 \pm 1.30 / 1.19$ & $-1.05 \pm 1.59 / 0.87$ & $0.51 \pm 1.57 / 0.80$ \\
A $\beta 40$ & $0.46 \pm 4.64 / 8.03$ & $0.05 \pm 0.67 / 1.53$ & $-1.28 \pm 7.83 / 8.34$ & $0.09 \pm 0.67 / 0.74$ \\
sAPPa/sAPP & $0.03 \pm 0.19 / 0.02^{b}$ & $0.41 \pm 0.59 / 0.88$ & $0.07 \pm 0.08 / 0.05^{a}$ & $0.66 \pm 0.53 / 0.44$ \\
A $\beta 42 / \mathrm{A} \beta 40$ & $-0.02 \pm 0.20 / 0.03$ & $0.21 \pm 0.71 / 1.11$ & $-0.03 \pm 0.04 / 0.06$ & $0.37 \pm 0.57 / 0.71$ \\
\hline
\end{tabular}

All data reported as result \pm upper CI/lower CI. Units for sAPP and sAPPa are ng/ml. Units for A $\beta 42$ and A $\beta 40$ are $\mathrm{pM}$.

${ }^{a}$ Difference is significant at $\mathrm{p}<0.05$.

${ }^{b}$ Difference is significant at $\mathrm{p}<0.05$, but "leave out extreme" validation removed this significance. 
Table 5

Characterization of Subjects for Baseline APP Derivative Analysis

\begin{tabular}{|l|l|l|l|l|}
\hline Group & Number of Subjects & Number of Females & Mean IQ & Mean Age (years) \\
\hline Idiopathic ASD & 11 & 2 & 50 & 11.8 \\
\hline FXS plus ASD & 12 & 2 & 45 & 11.9 \\
\hline
\end{tabular}


Table 6

Baseline Fragile X Syndrome versus Idiopathic Autism Concomitant Psychotropic Medication Use

\begin{tabular}{|l|l|l|}
\hline Drug & Fragile X Syndrome (N) & Idiopathic Autism (N) \\
\hline Risperidone & 4 & 4 \\
\hline Aripiprazole & 2 & 2 \\
\hline Fluoxetine & 2 & 1 \\
\hline Methylphenidate ER & 2 & 1 \\
\hline Mirtazapine & 2 & 2 \\
\hline Sertraline & 2 & 2 \\
\hline Clonidine & 2 & 3 \\
\hline Dexedrine & 1 & 0 \\
\hline Guanfacine & 1 & 2 \\
\hline Lisdexamphetamine & 1 & 1 \\
\hline Lorazepam & 1 & 0 \\
\hline Oxcarbazapine & 1 & 0 \\
\hline Gabapentin & 0 & 1 \\
\hline Mixed Amphetamine Salts & 0 & 1 \\
\hline
\end{tabular}


Table 7

Levels of Plasma A $\beta 42$ and A $\beta 40$ in Idiopathic ASD vs. Fragile X Syndrome Associated ASD Subjects

\begin{tabular}{l|c|c|c}
\hline Marker or Ratio & \multicolumn{2}{|c|}{ Level (relative to idiopathic autism) } & Hedge's $g$ \\
& Idiopathic Autism & Fragile X & \\
\hline $\mathrm{sAPP}$ & $1.00 \pm 1.05 / 0.53$ & $1.12 \pm 1.24 / 0.71$ & $0.07 \pm 0.60 / 0.79$ \\
$\mathrm{sAPPa}$ & $1.00 \pm 1.00 / 0.43$ & $1.09 \pm 0.80 / 0.39$ & $0.08 \pm 0.72 / 0.69$ \\
$\mathrm{~A} \beta 42^{b}$ & $1.00 \pm 0.19 / 0.14$ & $1.30 \pm 0.25 / 0.29$ & $0.67 \pm 0.63 / 0.70$ \\
$\mathrm{~A} \beta 40$ & $1.00 \pm 0.33 / 0.23$ & $1.22 \pm 0.28 / 0.26$ & $0.42 \pm 0.68 / 0.78$ \\
$\mathrm{sAPP} / \mathrm{sAPP}, \mathrm{c}$ & $1.00 \pm 0.20 / 0.16$ & $1.79 \pm 0.93 / 0.65$ & $0.68 \pm 0.38 / 0.57$ \\
$\mathrm{~A} \beta 42 / \mathrm{A} \beta 40$ & $1.00 \pm 0.12 / 0.18$ & $0.98 \pm 0.10 / 0.10$ & $0.09 \pm 0.74 / 0.81$ \\
\hline
\end{tabular}

All data reported as result \pm upper $\mathrm{CI} /$ lower CI

${ }^{a}$ Fragile $\mathrm{X}$ and idiopathic samples differed at $\mathrm{p}<0.05$.

${ }^{b}$ Fragile $\mathrm{X}$ and idiopathic samples for $\mathrm{A} \beta 42$ differed at $\mathrm{p}<0.10$.

${ }^{c}$ Hedge's $g$ greater than 0 at $\pm 95 \%$ confidence interval. 